\title{
Special Article: One Resident's Perspective on a Different Style of Psychopharmacological Practice
}

\author{
Michael Amiel, M.D. \\ North Florida Evaluation / Treatment Center, Gainsville Florida \\ Docteur J.P. Blayac \\ Hospital St. Charles, Montpellier Cedex, France
}

Follow this and additional works at: https://jdc.jefferson.edu/jeffjpsychiatry

Part of the Psychiatry Commons

Let us know how access to this document benefits you

\section{Recommended Citation}

Amiel, M.D., Michael and Blayac, Docteur J.P. (1990) "Special Article: One Resident's Perspective on a Different Style of Psychopharmacological Practice," Jefferson Journal of Psychiatry. Vol. 8 : Iss. 1 , Article 4.

DOI: https://doi.org/10.29046/JJP.008.1.001

Available at: https://jdc.jefferson.edu/jeffjpsychiatry/vol8/iss1/4

This Article is brought to you for free and open access by the Jefferson Digital Commons. The Jefferson Digital Commons is a service of Thomas Jefferson University's Center for Teaching and Learning (CTL). The Commons is a showcase for Jefferson books and journals, peer-reviewed scholarly publications, unique historical collections from the University archives, and teaching tools. The Jefferson Digital Commons allows researchers and interested readers anywhere in the world to learn about and keep up to date with Jefferson scholarship. This article has been accepted for inclusion in Jefferson Journal of Psychiatry by an authorized administrator of the Jefferson Digital Commons. For more information, please contact: JeffersonDigitalCommons@jefferson.edu. 


\title{
Special Article:
}

\section{One Resident's Perspective on a Different Style of Psychopharmacological Practice}

\author{
Michael Amiel, M.D. \\ Docteur J.P. Blayac
}

This article provides a comparison of psychopharmacological practices in the U.S. and France. The prescription as well as proscription of various classes of psychotropic drugs are considered. Even though the general guidelines of psychopharmacological practice remain the same, the details vary considerably and are determined especially by commercial factors.

\section{INTRODUCTION}

Though a comparison of current clinical psychopharmacological practices in France and the U.S. is an unaddressed topic, these contrasts may be quite striking to an American-trained psychiatrist. The following observations are based on my two month inpatient experience as a fourth-year psychiatric resident at a public psychiatric institution located in Montpellier, France (1987). This article was written in collaboration with Dr. Blayac who is one of the regional center directors for the French equivalent of the FDA.

Before I begin to discuss this topic, I think that the reader should be made aware of some fundamental differences between French and American psychiatry. French psychiatry is an integral part of a socialized form of medicine, which helps one understand the socioeconomic setting in which French psychopharmacology is practiced as well as these practices' financial constraints. This may also contribute to the practical pharmacological orientation one observes in a public setting, even where a psychodynamic orientation is very often theoretically proposed. An additional difference is that the French public sector combines academic and community psychiatry synonymously. This does not appear to have much bearing on psychopharmacological practice.

This article intends to alert the reader to a different sphere of psychopharmacological practices which may help the American clinician reassess what

The author would like to acknowledge the following persons: Carlos Muniz, M.D., Marijan Herjanic, M.D., Lindsay DeVane, Pharm D. 
he/she is doing presently in this country. Let me simply state that none of the following different practices are absolutely or uniformly followed in France but that the basic tendencies and mode of practice are consistent with what is currently considered acceptable in French psychiatry.

Therefore, in order to better understand the differences (Table 1) between psychopharmacological practices in France and the U.S., I will first consider their similarities.

\section{SIMILARITIES}

The similarities between the U.S. and France with respect to psychopharmacological practice reflect certain general universal guidelines of treatment. Antipsychotics are primarily indicated for psychoses. Lithium therapy is the first line drug in the prophylactic treatment of bipolar disorder. Antidepressants including polycyclic antidepressants and MAO inhibitors are indicated for major depression and relatively contraindicated in psychotic and bipolar disorders (1). Antianxiety agents including benzodiazepines, antihistamines, propanediols and barbiturates, are used to treat anxiety and sleep disorders.

\section{DIFFERENCES}

Neuroleptic Treatment

In the United States, one can say that it is a fairly common practice to place an acutely psychotic individual on one neuroleptic at a time (2), whose reasonable trial extends to a minimum of two or more weeks depending on the severity

TABLE 1.

Major Differences

\begin{tabular}{|c|c|c|}
\hline & US & France \\
\hline \multicolumn{3}{|l|}{$\begin{array}{l}\text { \# of Neuroleptics used at } \\
\text { one time }\end{array}$} \\
\hline Lithium Alternatives & Carbamazepine & Valpromide \\
\hline Commercialized and com- & Benztropine & Biperiden \\
\hline $\begin{array}{l}\text { monly used antichol- } \\
\text { linergic }\end{array}$ & Trihexyphenidyl & $\begin{array}{l}\text { Trihexyphenidyl (both } \\
\text { are piperidine deriva- } \\
\text { tives) }\end{array}$ \\
\hline \multirow[t]{2}{*}{ Antidepressants } & TCA & $\begin{array}{l}\text { TCA with amphetamine } \\
\text { like properties: } \\
\text { Amineptine }\end{array}$ \\
\hline & MAOI & $\begin{array}{l}\text { MAOI-A selective: } \\
\text { Toloxatone }\end{array}$ \\
\hline IM Benzodiazepines & Lorazepam & $\begin{array}{l}\text { Diazepam } \\
\text { Clorazepate }\end{array}$ \\
\hline
\end{tabular}


TABLE 2.

Neuroleptics

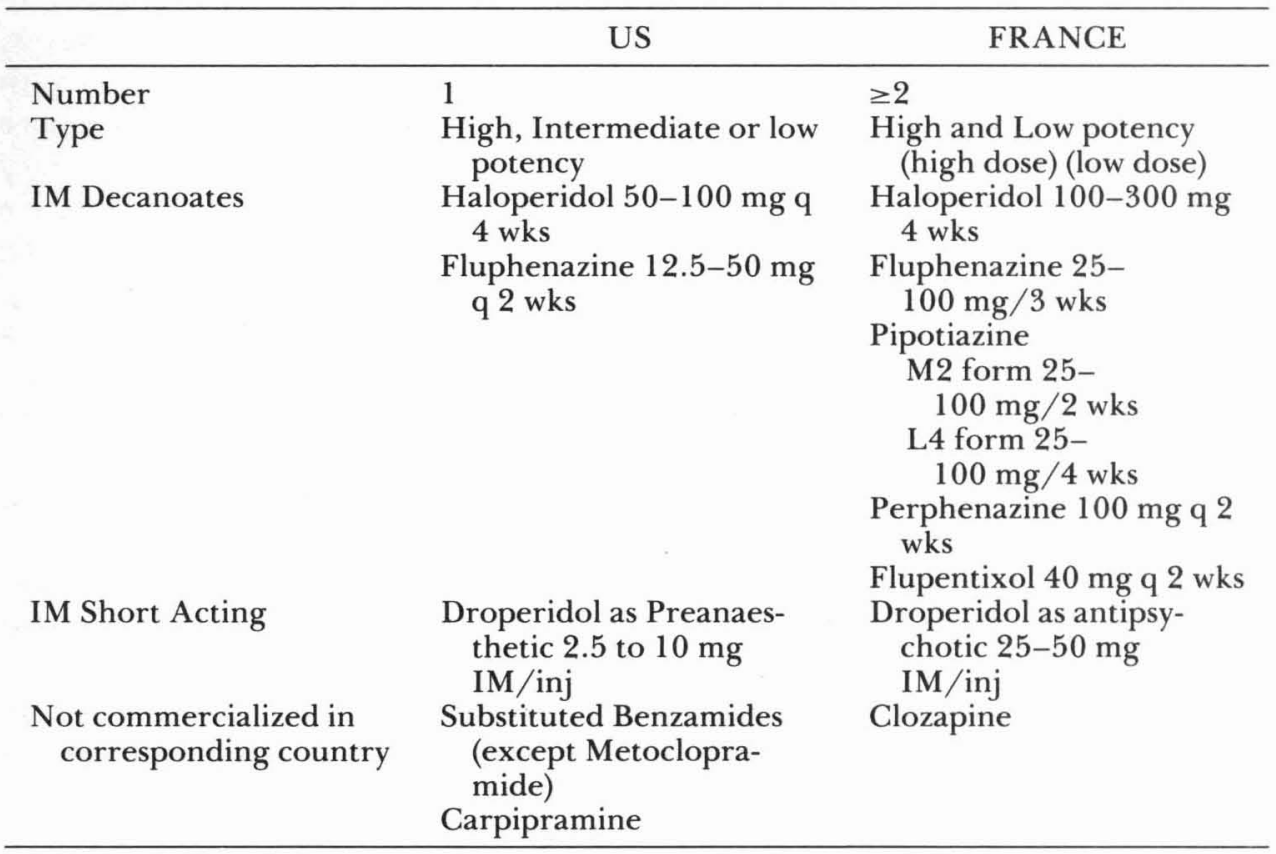

of impairment (2). Most recently, benzodiazepines with short half-lives (i.e. Lorazepam) are sometimes combined with neuroleptics during initial treatment $(3,4)$. It should be noted at this point that in the United States consideration of possible late onset tardive dyskinesia is commonly present in the clinician's mind when he prescribes neuroleptics, in part because of its forensic consequences (5).

On inpatient psychiatric units in France, it is quite common to treat schizophrenic patients concomitantly with two neuroleptics; there is usually one high potency neuroleptic such as Haloperidol, at doses ranging from 30 to $40 \mathrm{mg}$ per day, combined with relatively lower doses (under $150 \mathrm{mg}$ per day) of a low potency neuroleptic such as chlorpromazine (6). The sedating low potency neuroleptic is used for its tranquilizing effect. Tardive dyskinesia is a consideration; however, the legal implications are not a determinant or a deterrent in the evaluation of the medication's risks. The rationale for combining the two different classes of neuroleptics are the following:

a) Historically this mode of prescription dates back many years and is considered fairly conventional by both psychopharmacologists and clinical practitioners, although this association was studied in the 1960's and considered by many American authors such as Freeman (7) to be no more effective than monotherapy throughout the treatment's duration. 
b) The anticholinergic effects of the low-potency neuroleptic decreases the extrapyramidal side effects of the high-potency neuroleptic. The result is thought to produce a decreased instance of secondary side effects (8); other anticholinergic medications are, therefore, less necessary. This does not imply, however, that one never sees anticholinergic medications prescribed in association with high-potency neuroleptics. The latter brings us to the continuing debate over whether or not to combine anticholinergic medications with high-potency neuroleptics for prophylaxis of extrapyramidal side effects. This debate is active on both sides of the Atlantic $(2,6)$. Here, let me note that similar anticholinergic medications exist in both countries, but prescribing patterns differ (Table 1). For example, benztropine is rarely used in France; while biperiden, which has a shorter half life is commonly used in France, in both oral and depot forms $(9,10)$. The ultimate effect is the same but the choice of drug is commonly based more on commercial factors.

Another important note that must be made concerning the treatment of other side-effects secondary to neuroleptics, refers to orthostatic hypotension. In France this is systematically treated by a sympathomimetic drug known as heptaminol (6). Phenylephrine, presents this indication in France but is not used for this purpose in current common U.S. clinical psychiatric inpatient practice. In the U.S., patients are first advised to rise slowly from a sitting position; support hose or stockings are also sometimes suggested. Often the drug may be discontinued. IV infusion of a vasopressor agent, such as norepinephrine, may be recommended theoretically only in severe cases (2), given that postural hypotension usually occurs only during the first few days of treatment and is not ordinarily troublesome when the dose is given orally.

In the United States the depot forms of neuroleptics are commonly used. The fluphenazine decanoate dosage usually ranges from $25 \mathrm{mg}$ to $50 \mathrm{mg}$ IM every two weeks. Most recently, haloperidol decanoate has been marketed in this country and the initial maximum dose is $100 \mathrm{mg}$ IM every four weeks.

In France, depot neuroleptics have been used for many years. Not only do they have haloperidol and fluphenazine in this pharmaceutical preparation but they also use depot forms of other piperazine or piperidine phenothiazines (pipotiazine and perphenazine) as well as the depot form of the thioxanthine flupentixol (11). Higher doses of decanoate are usually prescribed, such as 100 to $300 \mathrm{mg}$ IM of haloperidol decanoate every four weeks, and 25-100 mg IM of fluphenazine decanoate every three weeks. Interestingly, decanoates are also indicated in lower doses for adolescent conduct disorders. I noted this clinical psychopharmacological practice while working in France; I was not, however, able to find justification for this practice in any of the literature. The rationale given behind this indication was that many of these adolescents are considered latent schizophrenics. Given their poor compliance with medications as well as the need for behavioral control of this anger prone population, the use of low-dose depot neuroleptics is thought to be quite helpful therapeutically for these patients. It is particularly interesting to note that in the United States, 
these same adolescents would most likely be given a trial of a tricyclic antidepressant.

In France, the frequent use of the butyrophenone droperidol for prompt control of psychotic agitation (6) is also notable, though in the United States it is used only as a pre-anesthetic medication (10). The doses used in the United States are lower (10) than those used in France. In practice, it is administered intramuscularly. Theoretically it may be given intravenously.

Finally, and most importantly, it should be noted that there exists in France an entire class of neuroleptics, called substituted benzamides (11). Metoclopramide is the only substituted benzamide available in the United States however, and is approved only for treatment of gastrointestinal disorders (10). Sulpiride and sultopride, which have existed for many years in Europe, are not available in the United States. The reason given for the non-approval of these drugs is that there is concern about long term toxicity, that they increase prolactin secretion to a higher degree than classical neuroleptics and that their superior antipsychotic effect is debatable. The literature has shown that these agents are effective antipsychotic drugs $(12,13)$. It is significant that in France bromocriptine is sometimes associated with sulpiride as a prophylaxis against galactorrhea (5), just as benztropine is associated prophylactically with haloperidol in the event of extrapyramidal side effects. Carpipramine represents another class of antipsychotic which has been commercialized in France since 1977 (14); it has antidepressant properties like sulpiride (6).

\section{Lithium Therapy}

There are not too many French/U.S. differences concerning the use and indications for lithium therapy. French clinicians are reluctant to use lithium for anything other than its primary indication of bipolar disorder. Because of the required biological surveillances, the latter is especially true in the public sector where compliance is questionable, and financial cost a consideration. As for alternate treatments, it can be noted that carbamazepine trials are rather recent in France (five years). However, valpromide, which is chemically related to valproic acid, has been formally recognized and commercialized in France since 1971 (14) as an alternate when lithium is contraindicated $(11,15)$.

\section{Antidepressants}

MAO inhibitors are seldom prescribed in France (16). There are several explanations for their proscription. Wine and cheese are an integral part of all meals in France which makes the use of MAOI's rather difficult even though it is recognized that only $20 \%$ or less of patients may develop a hypertensive crisis on a tyramine-containing diet. However, the main reason for the proscription of these drugs is that psychiatrists are seriously discouraged by anesthesiologists to prescribe them, because of their contraindication with drugs such as meperi- 
dine. There are no litigation issues involved here. Phenelzine sulfate was removed from the French commercial market in the 1970's because of insufficient use by practitioners. Tranylcypromine is still commercialized in France but very rarely prescribed. There is, however, a new MAO inhibitor, toloxatone, which has appeared on the French market in the past six years and is prescribed because of its selective MAOI-A activity (11). Toloxatone, has only slight and reversible tyramine potentiating effects and therefore, does not present the absolute restrictions associated with conventional MAO inhibitors.

Polycyclic Antidepressants As noted earlier, polycyclic antidepressants in France are characteristically used for major depression; however, there are certain differences that should be considered. First of all, benzodiazepines are quite often combined with antidepressants during the first two weeks of therapy (16). The rationale for this combination rests on the conclusion that high levels of anxiety during the first two weeks of treatment may contribute to suicide.

Second, an interesting practice on French inpatient units is to administer antidepressants intravenously (16). The rationale behind this practice is the following: 1) IV infusions decrease the risk of suicide, as the patient is not free to move about and leave the unit; 2) Having an IV infusion or a heparin lock has a placebo effect; 3) Pharmacologically, the therapeutic levels are achieved more rapidly, though the one to three week delay in antidepressant response is not shortened in these cases.

Third, the potentiation of the therapeutic effect of a tricyclic antidepressant by the addition of a thyroid hormone is not a common practice on French inpatient units, even though they recognize that it increases the blood level of the TCA (17). On the other hand, the addition of tryptophan to a tricyclic antidepressant is practiced (16); however, the doses of tryptophan are ten times smaller than recommendations given in British literature $(18,19)$.

Another association with a TCA concerns one of its anticholinergic side effects. Orally administered anetholtrithione commercialized as sulfarlem S 25 (14), is commonly used in France to treat dry mouth secondary to a TCA, MAOI, neuroleptic or other anticholinergic medications. In the U.S., locally applied pilocarpine is theoretically recommended (2). However, it is not commonly used, given its transitory relief, the patient's eventual tolerance, and the temporary nature of the autonomic side effects during early stages of treatment (2). Conversely, a product such as bethanechol, which is recommended for urinary hesitation in the U.S. (20), does not exist in France. According to Lambert (16), urinary hesitation is related to the dose of the drug or underlying prostatic hyperthrophy, and implies that these two factors are the ones which should be modified or treated to relieve the patient's discomfort.

Fourth, there does exist an antidepressant commercialized in France that has amphetamine-like properties, amineptine (14), which is very commonly used in major depression with psychomotor retardation. Amineptine differs from conventional cyclic antidepressants in its dopaminergic action (it can be 
hypothesized that sulpiride in lower doses also acts as an antidepressant by this same mechanism of action) (21). Amineptine has been commercialized in France since 1978 (14). The addition of amphetamine like drugs such as methylphenidate has been recognized in the U.S. as an adjunct in the treatment of refractory depression $(21,22,23)$, as well as for treatment of depression in the elderly. Still its efficiency when used alone, is debated by certain authors $(1,25,26)$. An interesting note is that methylphenidate was dropped from the French commercial market because of its addictive properties (27), and replaced by other drugs (fenetylline, fenozolone, prolintane) which are reportedly less effective therapeutically and have lesser side effects. The above perhaps explains why a TCA is more commonly used in France to treat attention deficit disorder with hyperactivity in children as opposed to stimulant drugs.

Finally, the TCA clomipramine has long been recognized as indicated in the treatment of obsessive compulsive disorder (commercialized in France since 1972) (14). It is commonly used for this disorder as well as affective illness. It just recently appeared on the U.S. market.

\section{Antianxiety Agents}

Benzodiazepines represent a class of drugs most frequently prescribed in the U.S. and France (26); however, they are not controlled substances in France (1 1) as they are in the U.S.A. (requiring a DEA number). Furthermore, the intramuscular form of short-acting benzodiazapines such as lorazepam are not available commercially in France; the latter is consistent with use of an IM short acting neuroleptic, such as droperidol, for acute agitation. The only intramuscular benzodiazepines available commercially in France (11) are diazepam and clorazepate. Their clinical indications, including alcohol detoxification, are the same as in the U.S.A. Meprobamate is still commonly used in France; one of its primary indications is also alcohol detoxification (29).

\section{CONCLUSION}

The similarities reflect that the same general guidelines and rules are respected by both countries. However, clinical psychopharmacological practice in the U.S. and France are quite different when one pays attention to its details. The relative lack of forensic considerations in France is such that neuroleptics are more widely and liberally used. The absence of legal constraints makes polypharmacy a more prominent issue. The simultaneous use of two or more neuroleptics, the common use of heptaminol for the treatment of orthostatic hypotension, the common use of anetholtrithione for the treatment of dry mouth and the use of bromocriptine for the treatment of secondary galactorrhea are all illustrations of French polypharmacy. Commercial factors are also at play in determining the presence or absence of a particular drug and, therefore, its use in common clinical psychopharmacological practice in the respective 
country, making this an issue in both France and the U.S. It is in this light that we may observe the absence of the following drugs from the U.S. market: heptaminol, anetholtrithione, sulpiride and sultopride, carpipramine, toloxatone, amineptine and valpromide to name a few. It is along this line of thought that we note the absence of buspirone, bethanechol and clozapine from the French market.

This paper does not address in any scientific or methodical fashion the comparative result of the different clinical psychopharmacological practices that I have outlined here. One would hope that awareness of the differences noted, which this paper attempts to provide, will lead to further detailed investigation of the comparative results observed in both countries. One would then hope that clinical practice would benefit from such a comparison and exchange of ideas.

\section{REFERENCES}

1. Davis JM: Antidepressant drugs, in Comprehensive Textbook of Psychiatry, H.I. Kaplan, BJ Sadock editors. Williams and Wilkins, Baltimore, MD, 1985

2. Davis JM: Antipsychotic drugs, in Comprehensive Textbook of Psychiatry, HI Kaplan, BJ Sadock editors. Williams and Wilkins, Baltimore, MD, 1985

3. Deberdt R: Lorazepam in the treatment of severe anxiety and anxiety associated with psychotic conditions. Curr Med Res Opin 1:296-300, 1973

4. Lenox R, Modell J, Weiner S: Acute treatment of manic agitation with lorazepam. Psychosomatics 27(1):28-31, 1986

5. Slovenko R: Law and psychiatry, in Comprehensive Textbook of Psychiatry, HI Kaplan, BJ Sadock editors. Williams and Wilkins, Baltimore, MD, 1985

6. Lambert P: Les Neuroleptiques, in Psychopharmacolgie Clinique, Les Medicaments Psychotropes, Privat editeur, France, 1980

7. Freeman H: The therapeutic value of combinations of psychotropic drugs. Psychopharm Bull 4(1):1-27, 1967

8. Colmart CH, Bridgman F, Girard B: La thioproperazine et la levomepromazine utilisees en association dans le traitement des psychoses chroniques. Eval Psychiat $34: 847-860,1969$

9. Dorosz P: Neurologie, in Guide Pratique des Medicaments, Maloine editeur. Anchor Brendon, Tiptree, England, 1987

10. Product Information. In Physicians' Desk Reference, 1987

11. Dorosz P: Psychiatrie, in Guide Pratique des Medicaments, Maloine editeur. Anchor Brendon, Tiptree, England, 1987

12. Alfredsson G, Harnryd C, Wiesel FA: Effects of sulpiride and chlorpromazine on depressive symptoms in schizophrenic patients, relationship to drug concentrations. Psychopharmacology 84:237-241, 1984

13. Mielke DH, Gallant DM, Roniger JJ, Kessler C, Kessler LR: Sulpiride: Evaluation of antipsychotic activity in schizophrenic patients. J Nerv Ment Dis 38:569-571, 1977

14. Monographies des specialites pharmaceutiques, in Dictionnaire Vidal OVP editeur, 1987

15. Lambert P: Les stabilisateurs thymiques et les traitements de la psychose maniacodepressive, in Psychopharmacolgie Clinique, Les Medicaments Psychotropes, Privat editeur. France, 1980 
16. Lambert P: Les antidepresseurs, in Psychopharmacologie Clinique, Les Medicaments Psychotropes, Privat editeur. Clamecy, France, 1980

17. Dorosz P: Endocrinologie, in Guide Pratique Des Medicaments, Maloine editeur. Anchor Brendon, Tiptree, England, 1987

18. Graham PM: Drug Combinations for Chronic Depression (letter) Br J of Psychiatry, Aug; 145:214, 1984

19. Barker WA, Eccleston D: The treatment of chronic depression; An illustrative case. Br J of Psychiatry Mar; 144:317-9, 1984

20. Pollack MH, Rosenbaum JF: Management of antidepressant-induced side effects: A practical guide for the clinician. J Clin Psychiatry 48(1):3-8, 1987

21. Standish-Barry HMAS et al: A randomized double blind group comparative study of sulpiride and amitriptyline in affective disorder. Psychopharmacology 81:258-260, 1985

22. Wharton RN, et al: A potential clinical use for methylphenidate with tricylic antidepressants. Am J Psychiat 127(12):1619-1625, 1987

23. Meyers B: Treatment of imipramine-resistant depression and lithium-refractory mania through drug interactions. Am J Psychiatry 135(11):1420-1421, 1978

24. Klein DF, et al: Clinical management of affective disorders, in Diagnosis and Drug Treatment of Psychiatric Disorders: Adults and Children. William and Wilkins, Baltimore, MD, 2nd Ed.

25. Katon W, Raskind M: Treatment of depression in the medically ill elderly with methylphenidate. Am J Psychiatry 137(8):963-965, 1980

26. Kaufmann $\mathbf{M}$, et al: Use of psychostimulants in medically ill depressed patients. Psychosomatics 23(8):817-819, 1982

27. Lambert P: Les psychostimulants et les nooanaleptiques, in Psychopharmacologie Clinique, Les Medicaments Psychotropes, Privat editeur. France, 1980

28. Balter MO, Levine J, Manheimer DI: Cross national study of the extent of antianxiety drug use. N Engl J Med 290:769-774, 1974

29. Lambert P: Sur Certains traitements de l'alcoolisme psychiatrique, in Psychopharmacolgie Clinique, Les Medicaments Psychotropes, Privat editeur. France, 1980 